\title{
Physiological patterns in early morning asthma
}

\author{
M. R. HETZEL, T. J. H. CLARK, AND K. HOUSTON \\ From the Lung Function Laboratory, Brompton Hospital, London SW3
}

\begin{abstract}
Hetzel, M. R., Clark, T. J. H., and Houston, K. (1977). Thorax, 32, 418-423. Physiological patterns in early morning asthma. Sixteen asthmatic patients who regularly showed early morning falls in peak expiratory flow rate of more than $25 \%$ were studied at 06.00 hours and 14.00 hours. At 06.00 hours considerable deterioration in static lung volumes and airways resistance occurred which was typical of an attack of acute asthma. Blood gas analysis showed less variation, with mild hypoxia and a wide alveslar-arterial oxygen tension gradient throughout the study. Diurnal variation was also seen in the response of maximal mid expiratory flow rates to the inhalation of helium/oxygen mixture in seven patients, but another seven were consistently non-responders. The overall pattern of results suggests that the calibre of both large and small airways decreased at night but improvement was more complete in large airways during the day.

Despite these findings patients had few symptoms at 06.00 hours when most of them showed marked reversibility after inhaling aerosol salbutamol. This phenomenon might account for the sudden nature of some asthma deaths as these often occur in the early morning. If this is the case, the minority of patients whose early morning decline in lung function was not immediately reversible would appear to be at greatest risk.
\end{abstract}

Large diurnal swings in peak expiratory flow rate (PEFR) and early morning wheezing are commonly seen in asthma patients and may be related to the high incidence of sudden asthma deaths in hospital in the early morning (Cochrane and Clark, 1975). We report physiological studies in a group of patients who showed this excessive diurnal variation.

\section{Patients and methods}

Sixteen asthmatic subjects (mean age $48 \cdot 2$, range 26-68 years) were studied in hospital while convalescing from exacerbations of asthma. Fourhourly ward readings of PEFR from 06.00 to 22.00 hours showed regular early morning falls of more than $25 \%$ of the best daily readings at 14.00 hours. Patients were studied on the same day at 06.00 and 14.00 hours. Sympathomimetic drugs were discontinued from 22.00 hours the previous night but steroid treatment was continued. Patients were woken at 06.00 hours and taken by wheelchair to the laboratory. All patients gave informed consent to the study.

Investigations were made in the following order: PEFR was measured as the mean of three readings with a Wright peak flow meter (Airmed). Functional residual capacity (FRC), vital capacity (VC), total lung capacity (TLC), and residual volume ( $\mathrm{RV})$ were recorded as the mean of three readings using the methods of Du Bois et al. (1956a) in a Pulmostar SMB constant volume plethysmograph (Fenyves and Gut Medizinische Electronik) equipped with a Houston $2000 \mathrm{XY}$ recorder (Advance Electronics). Inspiratory resistance (Du Bois, 1956b) was measured as the mean of five readings during quiet respiration at a flow rate of 1 litre $\mathrm{sec}^{-1}$. This was converted to its reciprocal, conductance, and expressed as a ratio to thoracic gas volume-specific conductance (SGaw). Transfer factor for carbon monoxide diffusion (TLCO) by the single breath technique (Ogilvie et al., 1957) and alveolar volume (VA, ie, the volume of lung available for helium dilution during 10 seconds breath holding) were measured concurrently with a Resparameter Mark 4 (P.K. Morgan) as the mean of two consistent readings. Forced expiratory volume in 1 second $\left(\mathrm{FEV}_{1}\right)$ and forced vital capacity (FVC) were measured as the mean of three readings at BTPS from a wedge spirometer (Vitalograph). Maximal expiratory flow volume curves (MEFV) (Hyatt et al., 1958; Hyatt 
and Black, 1973) were obtained from three consistent forced vital capacity manoeuvres into an Ohio 800 spirometer linked by an Ohio flow volume converter to a Tectronics DM64 storage oscilloscope. Maximal expiratory flow rate at $50 \%$ observed vital capacity $\left(\mathrm{V}_{\max 50}\right)$ was recorded at BTPS from the MEFV curve. The change after breathing a mixture of $21 \%$ oxygen and $79 \%$ helium was then measured (Despas et al., 1972). Patients inhaled three vital capacities of this mixture followed by tidal breathing for a further 3 minutes. MEFV curves were then repeated, taking an additional three vital capacities of gas between attempts.

After this first set of tests, 12 patients (cases 112) inhaled $200 \mu \mathrm{g}$ salbutamol from a pressurised aerosol (Ventolin) and repeated the protocol 10 minutes later. Patients then returned to the wards and resumed their usual treatment. The study was subsequently repeated at 14.00 hours. Cases 13 and 14, however, were chosen on clinical grounds as fit for treatment with sympathomimetic drugs to be further withheld until 14.00 hours, at which time they were studied before and then 10 minutes after inhaling $200 \mu \mathrm{g}$ salbutamol. Percutaneous arterial blood gas samples were also taken from seven patients (cases 1-6 and 9) at the end of each protocol at 06.00 and 14.00 hours but this was not repeated after salbutamol inhalation. Samples were analysed immediately in a $\mathrm{PH} /$ Blood Gas Analyser 165 (Corning). Alveolar-arterial oxygen gradient was calculated from an assumed respiratory quotient of $0 \cdot 8$.

The results of individual patients were compared by analysis as percentages of predicted values of Cotes (1975) with the exception of $\mathrm{V}_{\max }$ (Bo (Bass, 1973). $\mathrm{V}_{\mathrm{A}}$ was compared by the expression $\mathrm{V}_{\mathrm{A}} / \mathrm{TLC}$ (ie, the percentage of TLC available for helium dilution in 10 seconds' breathholding; in 80 measurements in normal subjects in this laboratory the mean value of this ratio was $95.6 \%$ Istandard deviation 4.8 ). TLco was corrected for changes in $\mathrm{V}_{\mathrm{A}}$ by calculating the diffusion constant $\mathrm{KcO}\left(\mathrm{T}_{\mathrm{LCO}} / \mathrm{V}_{\mathrm{A}}\right)$. A positive response to helium in $\mathrm{V}_{\max }$, was taken as a $>20 \%$ increase (Despas et al., 1972).

\section{Results}

Table 1 shows mean results at 06.00 and 14.00 hours as percentages of predicted values. The differences between them are also given in absolute units. In terms of predicted values, mean results for PEFR, FEV , $_{1}$ and SGaw had fallen by over $30 \%$ at 06.00 hours but FRC had increased by $23 \%$ and RV by $49 \%$. TLC increased by a mean 0.4 litre (range 0.02-1.84 litres) and $V_{A} /$ TLC $\%$ had fallen to $75 \%$ at 06.00 hours. $V_{\max _{50}}$ decreased by $12 \%$ predicted values. After breathing the helium mixture $\mathrm{V}_{\max }{ }_{50}$ increased by a mean $0.071 \mathrm{sec}^{-1}$ at 06.00 hours and by $0.221 \mathrm{sec}^{-1}$ at 14.00 hours.

Blood gas results in seven patients, who had a similar fall in $\mathrm{FEV}_{1}$ at 06.00 hours $(36 \%$ of predicted values) to the rest of the group, are shown in Table 2. The greatest change occurred in $\mathrm{Po}_{2}$ which fell a mean $0.57 \mathrm{kPa}(4.3 \mathrm{mmHg})$ at 06.00 hours. However, cases 1 and 6 had higher oxygen tensions at 06.00 hours and the range of change at 06.00 compared with 14.00 hours was -1.9 to $+1.6 \mathrm{kPa}(-14.2$ to $+12.0 \mathrm{mmHg})$. The mean alveolar-arterial oxygen tension gradient was 4.8 $\mathrm{kPa}(36.0 \mathrm{mmHg})$ at 06.00 hours and $4.3 \mathrm{kPa}$ $(32.3 \mathrm{mmHg})$ at 14.00 hours.

When cases 1-8 were given salbutamol after the first set of tests at 06.00 hours they rapidly improved during the next 10 minutes and achieved more than $50 \%$ of the eventual improvement in

Table 1 Diurnal variation in respiratory function tests in 16 asthmatic subjects

\begin{tabular}{|c|c|c|c|c|}
\hline Test & $\begin{array}{l}06.00 h \\
\text { Mean }( \pm S D) \text { percent predicted }\end{array}$ & $\begin{array}{l}14.00 \mathrm{~h} \\
\text { Mean }( \pm S D) \text { percent predicted }\end{array}$ & $\begin{array}{l}\text { Mean change at } 06.00 \mathrm{~h} \\
\text { Percent predicted }\end{array}$ & Absolute units \\
\hline $\begin{array}{l}\text { PEFR } \\
\text { FRC } \\
\text { VC } \\
\text { TLC } \\
\text { RV } \\
\text { SGaw } \\
\text { TLCo } \\
\text { VAlTLC\% }_{\text {A }} \\
\text { KCo } \\
\text { FEV } \\
\text { FVC } \\
\text { V }_{\max } 50\end{array}$ & $\begin{aligned} & 35.4(12 \cdot 2) \\
& 132.4(40 \cdot 5) \\
& 75 \cdot 3(25 \cdot 1) \\
& 111.1(23 \cdot 0) \\
& 177 \cdot 5(78 \cdot 7) \\
& 30.5(21 \cdot 1) \\
& 82.2(20 \cdot 6) \\
& 74.5(14 \cdot 3) \\
& 99 \cdot 8(15 \cdot 6) \\
& 42.4(12.9) \\
& 64.9(20 \cdot 1) \\
& 20.5(11 \cdot 7)\end{aligned}$ & $\begin{aligned} & 68 \cdot 7(18 \cdot 2) \\
& 109 \cdot 6(27 \cdot 8) \\
& 92 \cdot 9(23 \cdot 2) \\
& 106 \cdot 0(18 \cdot 7) \\
& 128 \cdot 1(55 \cdot 9) \\
& 77 \cdot 5(32 \cdot 3) \\
& 101 \cdot 5(19 \cdot 8) \\
& 89 \cdot 1(10 \cdot 7) \\
& 104 \cdot 1(17 \cdot 1) \\
& 73 \cdot 1(25 \cdot 6) \\
& 90 \cdot 4(26 \cdot 3) \\
& 32 \cdot 5(13 \cdot 3)\end{aligned}$ & $\begin{array}{r}-33 \cdot 0 \\
+22 \cdot 8 \\
-17 \cdot 6 \\
+5 \cdot 1 \\
-49 \cdot 4 \\
-47 \cdot 0 \\
-19 \cdot 3 \\
-4 \cdot 3 \\
-30 \cdot 7 \\
-25 \cdot 5 \\
-12 \cdot 0\end{array}$ & 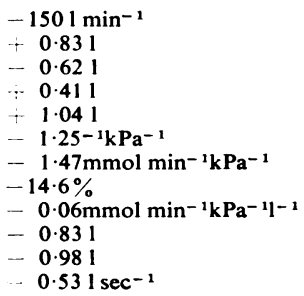 \\
\hline
\end{tabular}

PEFR_-peak expiratory flow rate; FRC_functional residual capacity; VC-vital capacity; TLC_total lung capacity; RV_residual volume

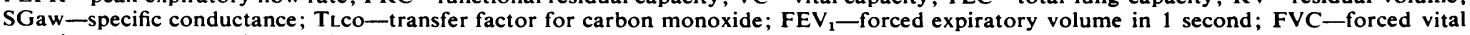
capacity; $V_{\max } 0^{-}-$maximal expiratory flow rate at $50 \%$ vital capacity; $V_{A}$-alveolar volume; Kco-diffusion constant. 
Table 2 Diurnal variation in blood gas results in 7 patients

\begin{tabular}{lccl}
\hline & $\begin{array}{l}\text { O6.00 } h \\
\text { Mean }( \pm S D)\end{array}$ & $\begin{array}{l}14.00 \mathrm{~h} \\
\text { Mean }( \pm S D)\end{array}$ & $\begin{array}{l}\text { Mean } \\
\text { change at } \\
06.00 h\end{array}$ \\
\hline $\mathrm{pH}$ & $7.45(0.03)$ & $7.44(0.04)$ & +0.01 \\
$\mathrm{PO}_{2}(\mathrm{kPa})$ & $9.36(2.1)$ & $9.93(1.4)$ & -0.57 \\
$\mathrm{O}_{2}$ saturation \% & $92.6(3.0)$ & $93.8(2.9)$ & -1.2 \\
$\mathrm{PCO}_{2}(\mathrm{kPa})$ & $4.6(0.4)$ & $4.5(0.5)$ & +0.1 \\
$\mathrm{HCO}_{3}-(\mathrm{mmol} \mathrm{1-1)}$ & $24.2(1.9)$ & $23.7(2.2)$ & +0.5 \\
Base excess (mmol 1-1) & $+1.7(1.9)$ & $+1.2(2.3)$ & +0.5 \\
Total CO $(\mathrm{mmol} \mathrm{1-1)}$ & $3.4(0.3)$ & $3.3(0.3)$ & +0.1 \\
A-aDO2 $(\mathrm{kPa})$ & $4.8(2.1)$ & $4.3(1.5)$ & +0.5 \\
\hline
\end{tabular}

A-aDO, alveolar-arterial oxygen tension difference 1 kilopascal $(\mathrm{kPa})=7 \cdot 5$ torr.

$\mathrm{FEV}_{1}$ that was subsequently seen between 06.00 and 14.00 hours. The remaining four patients (cases 9-12) showed little improvement 10 minutes after inhaling salbutamol but by 14.00 hours they had improved as much as the other patients. Ward readings of PEFR over the intervening period suggest that this was a gradual improvement. These two groups were labelled A and B respectively, and their differing responses to salbutamol are illustrated in Figure 1.

Cases 13 and 14 achieved an $\mathrm{FEV}_{1}$ of $32 \%$ and $35 \%$ predicted values respectively at 06.00 hours. Withdrawal of sympathomimetic drugs had little effect on results at 14.00 hours in case 14 whose $\mathrm{FEV}_{1}$ rose spontaneously to $77 \%$ and improved by only a further $5 \%$ after salbutamol inhalation. Case 13, however, still had an $\mathrm{FEV}_{1}$ of $32 \%$ which improved to $75 \%$ after inhaling salbutamol. Additional ward readings of PEFR conformed with these results.

Figure 2 shows MEFV curves of the 16 patients, corrected for observed TLC and RV, at 06.00 hours, 14.00 hours and after salbutamol inhalation whenever this was given. Two patients (cases 1 and 11) were consistent helium responders at all times, and seven patients (cases 6-9, 13, 14, and 16) were always non-responders. The remaining seven patients had a variable response at different times. All improved at 14.00 hours but only case 5 also responded after inhaling salbutamol, and case 3, having responded at 06.00 hours, became a nonresponder after salbutamol inhalation. Group A comprised one consistent responder, three nonresponders, and four variable responders. Group $B$ consisted of one responder, one non-responder, and two variable responders. Thus no relationship was demonstrable between patients' response to helium at 06.00 hours and their subsequent improvement after salbutamol inhalation.

\section{Discussion}

Large changes in $\mathrm{FEV}_{1}$, PEFR, FRC, VC, and $\mathrm{RV}$ of an order seen in acute asthma (Woolcock and Read, 1966) occurred spontaneously during the night in these patients. The mean increase in TLC (0.4 litre) at 06.00 hours was smaller than that seen in acute asthma by Woolcock and Read (1966) but the range was wide (0.02-1.84 litres). These large changes in TLC in some of our patients might suggest that their early morning attack had, in fact, been present for most of the night. Peress et al. (1976) have, however, shown that a large increase in TLC can occur and resolve rapidly in an induced asthma attack. We cannot, therefore, use the degree of hyperinflation that occurs as a means of comparing the duration of

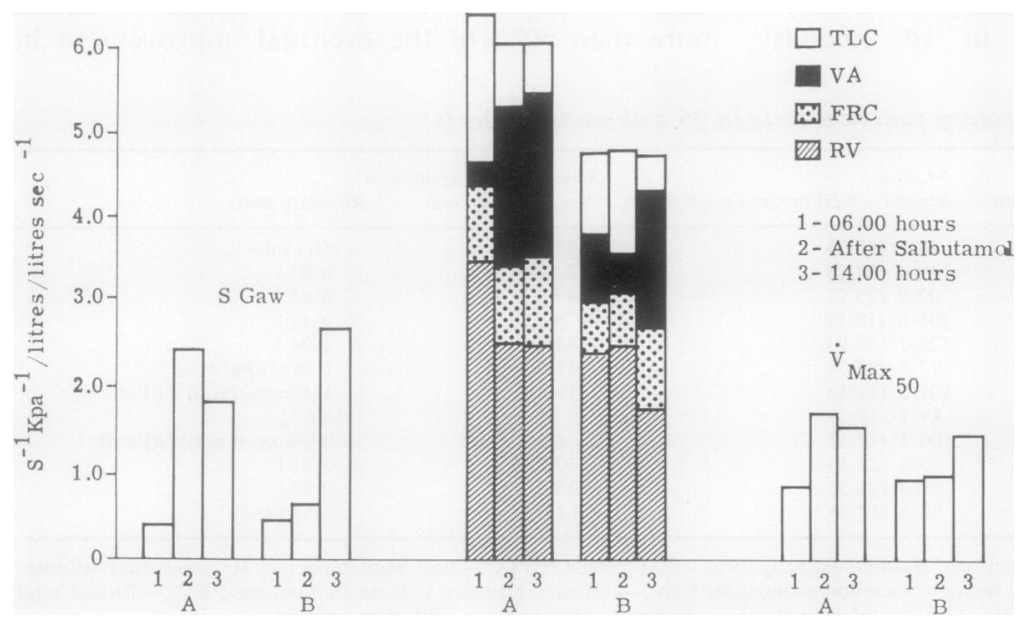

Fig. 1 Effect of salbutamol at 06.00 hours. Changes in mean results at 06.00 hours, at 06.00 hours after inhaling salbutamol, and at 14.00 hours.

Improvement in group $A(8$ patients) after salbutamol inhalation is of the same order as that subsequently seen at 14.00 hours. Little change occurs in group B (4 patients) on inhaling salbutamol but they eventually improve to a similar degree by 14.00 hours. 


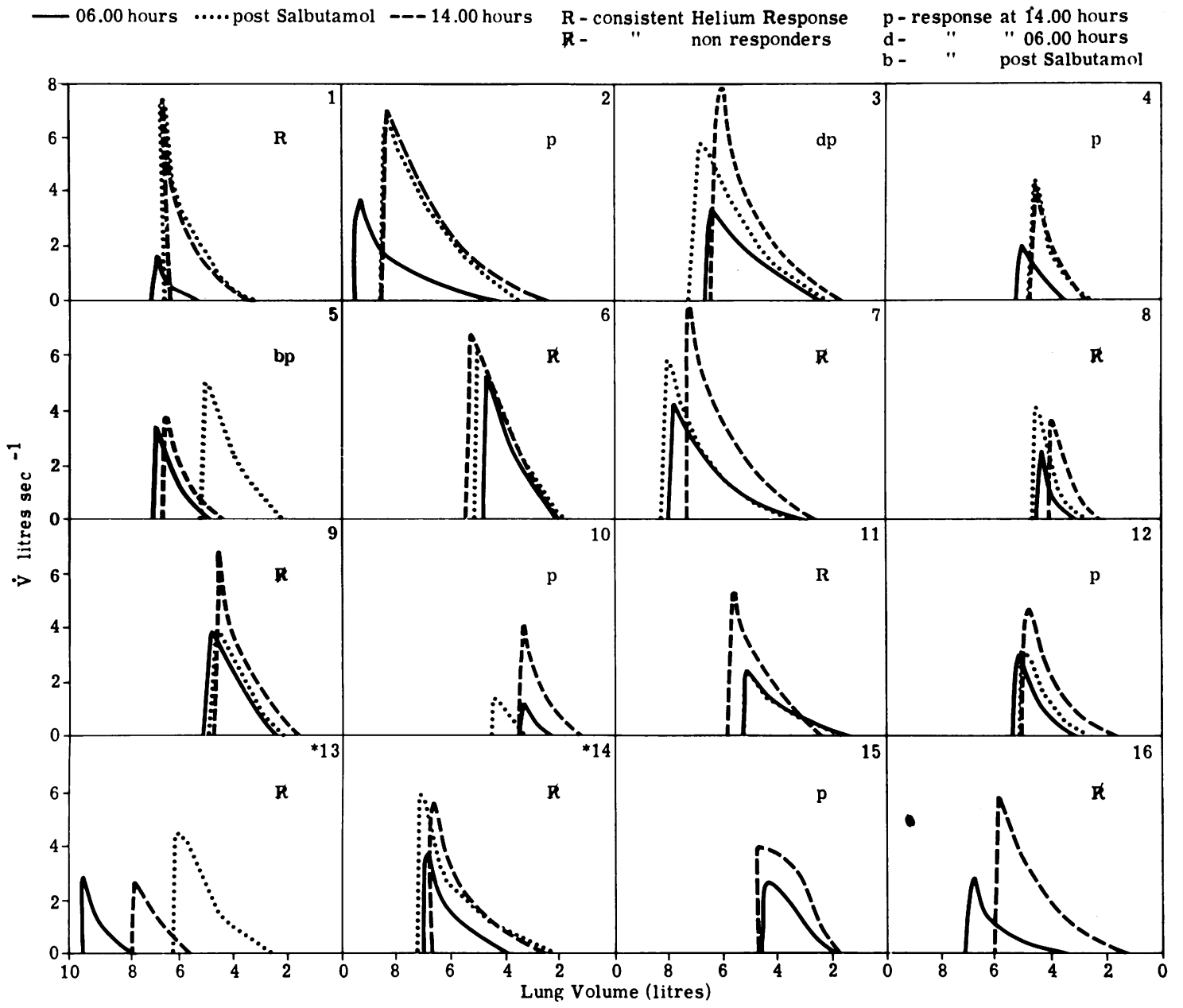

Fig. 2 Maximal expiratory flow volume curves. MEFV curves at 06.00 and 14.00 hours in all patients, after salbutamol aerosol at 06.00 hours in cases 1-12, and after salbutamol aerosol at 14.00 hours* in cases 13 and 14. Helium response is consistently seen in 2 patients $(R)$, consistently absent in 7 patients $(R)$, and in the remaining 7 patients it is variably present at 06.00 hours $(d)$, after salbutamol inhalation $(b)$, or at 14.00 hours $(p)$.

attacks of early morning asthma and acute asthma.

Blood gas results showed mild hypoxia throughout the study with only minor changes during the day. This slow improvement is analogous with the findings of Rees et al. (1968) in recovery from acute asthma. Alveolar-arterial oxygen gradients remained abno: mally wide at 14.00 hours and indicate persistent ventilation-perfusion imbalance. This was partly accounted for by low values for $V_{A} / T L C \%$. Surprisingly, two patients had higher oxygen tensions at $\mathbf{0 6 . 0 0}$ hours. Subsequent observations of PEFR during the night in these two patients revealed an unusually rapid fall before 06.00 hours. The relatively high oxygen tensions at 06.00 hours might therefore have resulted from blood gas tension lagging behind this very sudden change in airway calibre.

Results at 06.00 hours were compatible with a moderately severe acute asthma attack but patients were used to them and showed little distress. In most cases (group A) the early morning attack responded rapidly to aerosol salbutamol and the remainder (group B) improved spontaneously over a few hours. As we cannot distinguish between the physiological changes of early morning and acute 
asthma, the slow recovery and resistance to treatment typical of acute asthma may be due to the additional effect of mucus plugging.

\section{EFFECT OF TREATMENT}

Groups A and B showed very different responses to salbutamol at 06.00 hours. Although a whole spectrum of response might be expected in a large study, these two groups were quite sharply defined. Subsequent ward readings of the improvement in PEFR after aerosol salbutamol at 06.00 hours suggest that patients' reversibility was relatively constant at least during the current admission. Diurnal variation in group $\mathrm{A}$ is amplified by the lack of sustained treatment during the night which accentuates the early morning fall. Group B have a virtually autonomous rhythm. We also studied two patients (cases 13 and 14) in whom we felt that prolonged withdrawal of sympathomimetic drugs was justified in view of their mild symptoms. Fortuitously, they showed results which would have been expected if treatment were withheld from patients in groups A and B. As previously shown by Soutar et al. (1975), treatment with corticosteroids did not prevent marked diurnal variation in airway calibre in those patients who took them.

PROBABLE SITE OF AIRWAYS OBSTRUCTION According to the equal pressure point concept (Mead et al., 1967), maximal expiratory flow is dependent on the static recoil pressure of the lungs and the resistance of the upstream segment (RUS). Helium is less dense than air but of similar viscosity. It increases maximal expiratory flow when RUS is mainly due to turbulence and convective acceleration but not when laminar flow predominates as this is independent of gas density. Despas et al. (1972) have correlated helium response with obstruction predominantly in large airways with low total cross section area and mainly turbulent flow. Non-response is attributed to obstruction principally in small airways with large total area and laminar flow. These authors and Benetar et al. (1975) found helium response was constant in the individual patient. Seven of our patients, however, lost their helium response in the early morning as did a few of those studied by Chan-Yeung et al. (1976) after antigen challenge. Since laminar flow is less dependent on flow rate than turbulent flow, temporary loss of helium response might occur during severe airways obstruction when laminar flow would increase relative to turbulent flow. Our observation that helium response was greatest at $\mathbf{1 4 . 0 0}$ hours when initial values of $V_{\max ; 0}$ were highest and the demonstration by Benetar et al., and Chan Yeung et al., of a direct relationship between the magnitudes of $\mathrm{V}_{\max }{ }_{30}$ and helium response support this explanation. It would account for the absence of any correlation between helium response and the effect of salbutamol aerosol at 06.00 hours. Benetar et al. (1975) found that helium responders improved on further treatment but it seems that this is only a useful guide when airways obstruction is mild.

'Ten minutes' inhalation of helium is recommended for this test (Despas et al., 1972; Benetar et al., 1975) but 3 minutes or even three vital capacities have been found satisfactory (Hutcheon et al., 1974; Chan-Yeung et al., 1976). We confined exposure to 3 minutes to reduce spontaneous improvement during our lengthy sets of tests. A spirometer was also chosen for speed in recording flow volume curves at the expense of some inaccuracy from thoracic gas compression (Ingram and Schilder, 1966) but it is unlikely that these details have significantly altered the pattern of response.

At 14.00 hours near normal values for SGaw with persistently high RV and low mid expiratory flow rates were usually found. This is compatible with obstruction mainly in small airways (Bouhuys and van de Woestjne, 1970; McFadden and Linden, 1972). In seven patients this interpretation is supported by absence of helium response. At 06.00 hours low values for SGaw suggest considerable obstruction in large airways. In general, it seems that the calibre of all airways decreased during the night but improvement in the day was more complete in large airways.

\section{CLINICAL CONSIDERATIONS}

The decline in lung function at night in asthmatic patients may represent an exaggerated form of the slight circadian variation in airway calibre in normal subjects (McDermott, 1966; Reinberg and Gervais, 1972). It is demonstrable in patients with differing age, duration of asthma, atopic status, and smoking history. Despite considerable deterioration in lung function in the early morning, most patients notice only mild wheezing. This might explain why sudden death can occur in asthma patients who were apparently well (Macdonald et al., 1976). The similarity of the functional changes shown in these patients to those seen in acute asthma suggests that these tests do not detect special features of mucus plugging which may be responsible for the clinical differences between early morning asthma and status asthmaticus. Mucus plugging may be involved in 
the resistance of the minority of cases of early morning asthma to inhaled salbutamol (group B). These patients are probably rarer than our study suggests as they were investigated during long admissions occasioned by their intractable asthma. They appear to be at greatest risk of sudden death at home as they would be unlikely to reverse a severe early morning attack by inhaling aerosols of sympathomimetic drugs.

We thank the physicians of Brompton Hospital for permission to study patients under their care.

\section{References}

Bass, H. (1973). The flow volume loop: normal standards and abnormalities in chronic obstructive pulmonary disease. Chest, 63, 171-176.

Benetar, S. R., Clark, T. J. H., and Cochrane, G. M. (1975). Clinical relevance of the flow rate response to low density gas breathing in asthmatics. American Review of Respiratory Disease, 111, 126-134.

Bouhuys, A. and van de Woestijne, K. P. (1970). Respiratory mechanics and dust exposure in byssinosis. Journal of Clinical Investigation, 49, 106118.

Chan-Yeung. M., Abboud, R., Ming Sound Tsao, and Maclean, L. (1976). Effect of helium on maximal expiratory flow in patients with asthma before and during induced bronchoconstriction. American Review of Respiratory Disease, 113, 433-443.

Cochrane, G. M. and Clark, T. J. H. (1975). A survey of asthma mortality in patients between ages 35 and 64 in the Greater London hospitals in 1971. Thorax, 30, 300-305.

Cotes, J. E. (1975). Lung Function. Assessment and Application in Medicine, 3rd ed. Blackwell Scientific Publications, Oxford.

Despas, P. J., Leroux, M., and Macklem, P. T. (1972). Site of airway obstruction in asthma as determined by measuring maximal expiratory flow breathing air and a helium oxygen mixture. Journal of Clinical Investigation, 51, 3235-3243.

Du Bois, A. B., Botelho, S. Y., Bedell, G. N., Marshall, R., and Comroe, J. H., Jr. (1956a). A rapid plethysmographic method for measuring thoracic gas volume. Journal of Clinical Investigation. 35, 322326.

Du Bois, A. B., Botelho, S. Y., and Comroe, J. H., Jr. (1956b). A new method for measuring airway resistance in man using a body plethysmograph. Journal of Clinical Investigation, 35, 327-335.

Hutcheon, M., Griffin, P., Levison, H., and Zamel, N. (1974). Volume of isoflow. A new test in detection of mild abnormalities of lung mechanics. American Review of Respiratory Disease, 110, $458-465$.
Hyatt. R. E. and Black, L. F. (1973). The flowvolume curve. American Review of Respiratory Disease, 107, 191-199.

Hyatt. R. E., Schilder, D. P., and Fry, D. L. (1958). Relationship between maximal expiratory flow and degree of lung inflation. Journal of Applied Physiology. 13, 331-336.

Ingram, R. H., Jr. and Schilder, D. P. (1966). Effect of thoracic gas compression on the flow-volume curve of the forced vital capacity. American $R e$ view of Respiratory Disease, 94, 56-63.

McDermott. M. (1966). Diurnal and weekly cyclical changes in lung airways resistance. Journal of Physiology, 186, 90P-92P.

Macdonald, J. B., Seaton, A., and Williams, D. A. (1976). Asthma deaths in Cardiff, 1963-74: 90 deaths outside hospital. British Medical Journal, 1, 14931495.

McFadden, E. R., Jr. and Linden, D. A. (1972). A reduction in maximum mid-expiratory flow rate: a spirographic manifestation of small airway disease. American Journal of Medicine, 52, 725-737.

Mead. J., Turner, J. M., Macklem. P. T.. and Little, J. B. (1967). Significance of the relationship between lung recoil and maximum expiratory flow. Journal of Applied Physiology, 22, 95-108.

Ogilvie. C. M., Forster, R. E., Blakemore, W. S.. and Morton, J. W. (1957). A standardised breathholding technique for the clinical measurement of the diffusing capacity of the lung for carbon monoxide. Journal of Clinical Investigation, 36, $1-17$.

Peress, L., Sybrecht, G., and Macklem, P. T. (1976). The mechanism of increase in total lung capacity during acute asthma. American Journal of Medicine. 61, 165-169.

Rees, H. A.. Millar, J. S., and Donald, K. W. (1968). A study of the clinical course and arterial blood gas tensions of patients in status asthmaticus. Quarterly Journal of Medicine. 37, 541-561.

Reinberg, A. and Gervais, P. (1972). Circadian rhythms in respiratory functions with special reference to human chronophysiology and chronopharmacology. Bulletin de Physio-Pathologie Respiratoire, 8, 663-677.

Soutar, C. A.. Costello. J., Ijaduola, O., and Turner Warwick, M. (1975). Nocturnal and morning asthma. Relationship to plasma corticosteroids and response to cortisol infusion. Thorax, 30, 436 .

Woolcock, A. J. and Read. J. (1966). Lung volumes in exacerbations of asthma. American Journal of Medicine. 41, 259-273.

Requests for reprints to: Dr. M. R. Hetzel, Lung Function Laboratory, Brompton Hospital, London SW3 